\title{
Evaluating engagement with graduate outcomes across higher education institutions in Aotearoa/New Zealand
}

\author{
Spronken-Smith, R. , Bond, C. , McLean, A. , Freilick, S. , Smith, \\ N. , Jenkins, M. and Marshall, $S$. \\ Author post-print (accepted) deposited by Coventry University's Repository \\ Original citation \& hyperlink: \\ Spronken-Smith, R. , Bond, C. , McLean, A. , Freilick, S. , Smith, N. , Jenkins, M. and Marshall, \\ S. (2015) Evaluating engagement with graduate outcomes across higher education \\ institutions in Aotearoa/New Zealand. Higher Education Research \& Development, volume \\ 34 (5): 1014-1030 \\ http://dx.doi.org/10.1080/07294360.2015.1011098
}

DOI $\quad 10.1080 / 07294360.2015 .1011098$

ISSN $\quad 0729-4360$

ESSN $\quad 1469-8366$

Publisher: Taylor and Francis

This is an Accepted Manuscript of an article published by Taylor \& Francis in Higher Education Research \& Development on $9^{\text {th }}$ March 2015, available online: http://www.tandfonline.com/10.1080/07294360.2015.1011098

Copyright $(\subset$ and Moral Rights are retained by the author(s) and/ or other copyright owners. A copy can be downloaded for personal non-commercial research or study, without prior permission or charge. This item cannot be reproduced or quoted extensively from without first obtaining permission in writing from the copyright holder(s). The content must not be changed in any way or sold commercially in any format or medium without the formal permission of the copyright holders.

This document is the author's post-print version, incorporating any revisions agreed during the peer-review process. Some differences between the published version and this version may remain and you are advised to consult the published version if you wish to cite from it. 


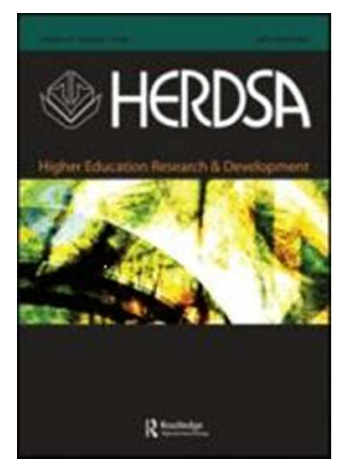

Evaluating engagement with graduate outcomes across higher education institutions in Aotearoa/New Zealand

\begin{tabular}{|r|l|}
\hline Journal: & Higher Education Research \& Development \\
\hline Manuscript ID: & CHER-2014-0096 \\
\hline Manuscript Type: & Article \\
\hline Keywords: & $\begin{array}{l}\text { Graduate attributes, Higher education policy, Academic development, } \\
\text { Evaluation }\end{array}$ \\
\hline \multicolumn{2}{|l}{} \\
\hline
\end{tabular}

SCHOLARONE

Manuscripts

URL: http://mc.manuscriptcentral.com/cher Email: diana.herd@hotmail.co.nz 


\title{
Evaluating engagement with graduate outcomes across higher education institutions in Aotearoa/New Zealand
}

\begin{abstract}
Our research addressed two aims: to develop a systematic way to evaluate institutional engagement with graduate outcomes; and to explore such engagement in higher education institutions in Aotearoa/New Zealand. An online survey was completed by 14/29 institutions with nine follow-up interviews to gather information on institutional engagement with graduate outcomes. Using a maturity modelling approach with indicators of planning, systems, delivery, assessment, evaluation and professional development support for graduate outcomes, we assessed the level of engagement for each indicator in each institution. Results revealed patchy engagement across the polytechnic and university sectors. There was strong engagement with the planning, systems and delivery of graduate outcomes, particularly in the polytechnic sector, but much lower engagement with their assessment and evaluation, and overall, weak engagement with professional development support for graduate outcomes. Some mechanisms for promoting engagement with graduate outcomes were strong external drivers, a teachingfocussed culture, strong leadership from the top and enabling structures. Our findings can be used to inform institutional policies and practices in order to support not only compliance, but, more importantly, engagement with the graduate outcome agenda to improve the student learning experience.
\end{abstract}

\section{Introduction}

In Europe, North America and Australia at least, graduate outcomes have been given high priority in higher education agendas. Behind the graduate outcome agenda in these regions is a great deal of funding, commitment and general agreement that graduate outcomes are important, but is this the case in Aotearoa/New Zealand? We believe that Aotearoa/New Zealand may lag significantly behind these global developments in both research and practice - particularly in the university sector. For instance, Aotearoa/New Zealand-based empirical research or sector wide conversations about graduate outcomes have been almost non-existent. However, this picture differs significantly in other parts of the tertiary sector, such as the Private Training Establishments, where funding relies on educational performance including evidence of learners' achievement of graduate profiles at the programme level, the value of outcomes for stakeholders 
(including learners), and how programmes meet the needs of learners (see reports at http://www.nzqa.govt.nz).

Graduate attributes have been described variously as graduate outcomes, profiles, or generic, transferable, employability or soft skills (de la Harpe et al. 2009). A well cited definition is that by Bowden et al. (2000, p. 3) who said that "graduate attributes are the qualities, skills and understandings a university community agrees its students would desirably develop during their time at the institution and, consequently, shape the contribution they are able to make to their profession and as a citizen." Thus generic graduate attributes go beyond disciplinary expertise or technical knowledge that has traditionally formed the core of most university courses. "They are qualities that also prepare graduates as agents of social good in an unknown future" (Bowden et al., 2000, p3). In this article we use the term 'graduate attribute' (GA) to refer to a specific outcome, quality or skill. The term 'graduate profile'(GP), refers to the summation of GAs, at either the institutional level (GPI), which defines a set of generic attributes that all graduates from the institution should acquire, or at the programme level (GPP), defining a list of GAs specific to the programme. Finally, we use the term 'graduate outcome' (GO) as an umbrella term, to encompass both graduate attributes and graduate profiles, as shown in Figure 1.

[Figure 1 about here]

\section{Recent history of the graduate outcome agenda}

In the early 1990s employers and researchers were concerned that universities were not producing graduates who were equipped for work. At the same time, issues were arising about the comparability of education systems in Europe. But underlying these initiatives was a more general concern about national prosperity and development (see Barrie, 2006; Bologna Declaration, 1999). To address these concerns, in 1999 European education ministers met in Bologna, Italy, with a key outcome being a declaration that aimed to establish a European Higher Education area by the year 2010 by means of 'harmonization' (Dale, 2008) of the disparate systems of higher education in the region. Part of the 'Bologna Process' as it became known, was to promote cooperation in ensuring quality via the development of comparable criteria and assessment methodologies for collegiate learning. Out of the Bologna Process came a joint quality initiative that led to the generation of the so-called 'Dublin descriptors', which were a framework of comparable and compatible qualifications for higher education systems (Kehm, 2010). 
Following on from the Bologna Process was the 'Tuning Project' (González \& Wagenaar, 2003), which, in line with the harmonization theme of Bologna, sought to 'tune' structures in Europe with the aim of aligning curricula, programmes and teaching and to integrate quality standards into these. Each course, degree or programme was to have a set of learning outcomes specified and there was a planned shift from teacher-centred to student-centred approaches. Through this tuning process, the detail of how graduates might be equipped for work was able to be mapped out via learning outcomes and curricular experiences. The Tuning Project was initiated in Europe and then, late in 2008, the Lumina Foundation began "Tuning USA" working with institutions in three states (Indiana, Minnesota and Utah) to draft learning outcomes and map these into the curriculum (see Adelman, 2008; Adelman et al., 2011).

Around the same time as the European Bologna Process, a series of reports emerged in Australia, highly critical of how underprepared university graduates were for the workplace (e.g., Hager, Holland \& Beckett, 2002). In the ensuing years, there was a great deal of research on graduate outcomes in Australian universities (e.g. Barrie 2004, Bath et al., 2004, de la Harpe et al. 2000, Pitman \& Broomhall 2009), much of which was calling for a systematic approach to embed graduate outcomes across curricula, in order to realise desired graduate profiles. Subsequently the Australian Qualifications Framework (AQF) oversaw the development of a national policy for regulated qualifications in Australian education and training, involving minimum outcomes for subjects and qualifications (AQF, 2011). This policy was approved in 2011.

So, particularly across Europe, North America and Australia there has been a great deal of momentum behind a graduate outcome agenda and consequently there has been much research on curriculum renewal and course design, ascertaining how best to engage with graduate outcomes. But there is a lack of empirical research about engagement with graduate outcomes at the institutional level, although several researchers have explored how to promote engagement with graduate outcomes at the institutional level. For example, Sharp and Sparrow (2002) listed 11 factors necessary for successful implementation: giving a high priority to graduate outcome initiatives; needing at least two years to implement; customisation of graduate attributes within disciplines; leadership through a task force; change embedded in course review and development processes; case studies being a useful mechanism for progress; implementation to focus on a few graduate attributes rather than all at once; the need for professional development support; and serious engagement with the teaching and learning process. Barrie, et al., (2009) and Hughes and Barrie (2010), in a large National Graduate Attributes Project across 39 Australian universities, identified eight systemic determinants for achieving graduate attributes, presented in a pyramid 
shape. At the base was conceptualisation, with a need for extensive institution-wide conversations about the meaning of graduate attributes, why they were important, and whose responsibility it was to implement them, with the second tier being wide stakeholder involvement. The implementation phase included staff development to support curriculum renewal around graduate attributes, a whole of programme approach to curriculum renewal, graduate attributes being embedded in assessment, and quality assurance to ensure attainment of graduate attributes. The final and top part of their pyramid was student-centredness, with the need for students to be actively engaged as partners in the assessment of graduate attribute process.

But what about engagement with, and research on, graduate outcomes in higher education institutions in Aotearoa/New Zealand? The tertiary education sector had been largely silent on the graduate outcome agenda until the last six years. In 2008 the New Zealand Qualifications Authority (NZQA) began a 'Targeted Review of Qualifications at Levels 1-6' in order to "ensure that New Zealand qualifications were useful and relevant to current and future learners, employers and other stakeholders" (NZQA, 2013). The result was the development of a New Zealand Qualifications Framework (NZQF), which requires all qualifications that are quality assured to specify Outcome Statements which include three elements:

- Graduate profiles that identify the expected learning outcomes of a qualification. This is captured in notions of what a learner will know and understand and be able to do when they achieve the qualification.

- Education pathways that identify other qualifications that a graduate could enrol into after completing this qualification. Where qualifications are standalone, and do not prepare graduates for further study, the outcome statement should make this clear.

- Employment pathways or contributions to the community that identify the areas in which a graduate may be qualified to work, or the contribution they may make to their community (NZQA, 2011, p. 7).

The Education Act was amended in August 2011 to require all quality assured qualifications in New Zealand to be listed on the NZQF and gave NZQA the power to make rules covering all qualifications listed - both university and non-university. Transition arrangements mean that by the end of 2015 all qualifications listed on the NZQF must meet the relevant new listing requirements which include specifying formal Outcome Statements.

Thus there is now a legislated requirement for degree-granting institutions in Aotearoa/New Zealand to specify Outcome Statements that include graduate profiles, and educational and 
employment pathways. While NZQA administers quality assurance for all non-university tertiary education organisations, Universities New Zealand is responsible for quality assurance of all universities, and approves qualifications developed by them. The Committee on University Academic Programmes (CUAP) oversees approval and reviews of new programmes. They must now ensure that university qualifications specify graduate outcomes in the format required for the NZQF.

Whilst non-university tertiary education organisations have been working with a graduate outcome agenda through NZQA, it is a new requirement for universities. Policy is now in place, but what is the practice? As noted earlier, there is a lack of research discussing whether higher education institutions in Aotearoa/New Zealand provide such outcome statements and if and how these might be translated into the curriculum. Moreover, we have found no systematic way to evaluate the level of engagement with graduate outcomes by institutions. Accordingly, our research has two aims: first to develop a systematic way to gauge the level of engagement with graduate outcomes by institutions; and second to use this method to identify the current level of engagement with graduate outcomes by higher education institutions in Aotearoa/New Zealand.

\section{Methods}

To determine engagement with the graduate outcome agenda, we undertook a stocktake across the 29 higher education institutions within Aotearoa/New Zealand as part of a national project on graduate outcomes (XXXX., 2013). The purpose of the stocktake was an exploratory analysis of current policies and practices regarding graduate outcomes. The stocktake had two parts: an online survey; and interviews with academic leaders of teaching and learning.

First we administered an online survey to 29 higher education institutions within Aotearoa/New Zealand, including eight universities, three wānanga ${ }^{1}$ and 18 polytechnics. An email letter of invitation was sent to the 29 academics with positions of responsibility for teaching and learning e.g., leaders of educational development units, deans, deputy deans etc., with follow-up email reminders sent at appropriate intervals. These academics, hereafter referred to as leaders, were targeted as participants because they tend to have a very good grasp on institutional policies and practices and are often charged with enacting institutional initiatives for curriculum renewal.

The survey was divided into six sections:

\footnotetext{
${ }^{1}$ Wānanga are publicly owned institutions that provide tertiary education in a Māori cultural context.
} 
1. Institutional characteristics

2. Presence of graduate outcomes (attributes and profiles) in the institution

3. Development of graduate outcomes in the institution

4. Use of graduate outcomes in the institution

5. Measurement of graduate outcomes in the institution

6. Overall engagement with graduate outcomes

The respondents were sometimes unsure of policies and practices across the institution, but gave their best estimate of the development and use of graduate outcomes within the institution. The leaders were also careful to say that often their views were personal rather than necessarily representing those held across the institution. However, such leaders were typically involved in developing and/or implementing strategies for graduate outcomes, so they were the key people to consult regarding graduate outcome policy and practice.

Second, we conducted follow-up interviews with the leaders in four universities and five polytechnics, to further explore how the institutions were engaging with graduate outcomes. Interviews were conducted by phone and were recorded. The audio files were transcribed verbatim and sent to participants for checking. To ensure anonymity of institutions, each is coded as $\mathrm{P}$ - polytechnic or $\mathrm{U}$ - university, and given a number.

Survey data were tabulated and graphed. The freeform comments from the survey data and the interview transcripts were analysed using Thomas's (2006) general inductive approach. This approach involves first finding themes in relation to the research objectives and secondly determining other themes that are apparent in these data.

Finally, we developed a systematic way to assess the level of institutional engagement with graduate outcomes, drawing on the concept of 'e-Learning Maturity Modelling (eMM)' (see Marshall \& Mitchell, 2003). The Maturity Model proposes that for an institution to be effective in a particular area of work, it must be engaged in processes that are reproducible and sustainable. To apply the model, the facets contributing to engagement are teased out and analysed separately. We determined six indicators of engagement with graduate outcomes: planning; systems to embed them; delivery; assessment; evaluation of attainment; and professional development support. Critical analysis of survey and interview data enabled a professional judgement to be made regarding level of engagement for each indicator, with triangulation from members of the research team. We used a five-point colour rating to indicate, 
in a qualitative sense, the level of engagement or embedding of graduate outcomes, ranging from dark blue/black for very strong through to light blue/grey, for very weak.

\section{Engagement with the Graduate Outcome Agenda \\ Institutional characteristics}

Fourteen institutions completed the survey, giving a response rate of $48 \%$, but not all respondents answered every question. Of the 14, half were universities, giving a very good representation from this sector ( $7 / 8$ or $88 \%$ ), a lower representation from the polytechnic sector (7/18 or $39 \%)$. Unfortunately, there was no representation from wānanga.

On a scale of very strong to very weak, of the 14 institutions, five (all universities) identified as having a very strong research culture, three institutions were strong (one university and two polytechnics), four were reasonable (one university and three polytechnics), and one each indicated weak (a polytechnic) or very weak (another polytechnic) (Figure 2). Regarding teaching culture, three institutions indicated a very strong teaching culture (two polytechnics and one university), five had a strong teaching culture (all polytechnics), four had a reasonable teaching culture (all universities) and two universities said they had a weak teaching culture.

[Figure 2 about here]

\section{Graduate outcomes in institutions - presence and policies}

One of the 14 institutions did not offer degree programmes - rather they taught two year diplomas that articulated to degrees with a partner university. Of the 13 degree-granting institutions, three universities had an institutional graduate profile (GPI), 12 institutions had graduate profiles for all degree programmes (i.e. GPPs) and one had graduate profiles for some degrees.

There were a range of outcomes identified by institutions for their graduates in their profiles. These included graduates being a global citizen; a critical thinker; a life-long learner; an independent learner; a scholar; a leader; caring, well-rounded and creative; and connected and ready for the workplace. As one respondent commented:

graduates will have acquired increased general and specific knowledge; a global perspective; information seeking and analysis capability; research; and 
presentation skills... graduates will have developed self-esteem and experience to contribute to the unique dual heritage of Aotearoa New Zealand (P2).

Three polytechnics and one university valued distinctiveness so that their graduates stand out from the crowd.

When asked why their institution has graduate outcome statements, all said they had them because of either New Zealand Qualifications Authority (NZQA) or Committee on University Academic Programmes (CUAP) requirements (Figure 3). Moreover, eight said they had them to help students making an informed choice in regard to their qualification and career (P3, P4, P5, P6, P7 and U2, U5, U6), and also to help and direct staff in their teaching and curriculum development (P3, P4, P5, P6 and U1, U4, U6). Stakeholders were another important reason for having graduate outcomes (P2, P3 and U4, U6), with one commenting "It is a commitment to our bicultural focus; a commitment to the community: and knowledge of soft skills that the employers want" (P2). Governance and good practice were the motivator for two universities (U4 and U6) to include GPPs and also to help prioritise academic staff resources. The need to comply with national regulatory bodies was another motivator (P5, P6 and U3, U6) as illustrated by the comment "I suspect we have them because of compliance issues" (U3).

[Figure 3 about here]

When asked whether there had been any recent strategic shifts in the institutional 'game plan' that might prioritise graduate outcomes, five said there had been (P2, P4, P5 and U2, U6). Such shifts though might be indirect, as illustrated by this comment:

not specifically or directly. However indirectly there is an increasing emphasis on examining graduate attributes from the perspective of the contribution that graduates make to our communities in ways economic; social and otherwise. This is producing an imperative for greater inclusion of graduate attributes in organisational thinking and strategy (P1).

\section{Development of graduate outcomes}

Six institutions (P2, P4, P5 and U2, U4, U6) said they had developed an institutional graduate profile (GPI) of generic graduate attributes as an institutional initiative. For example, the respondent from U4 commented "The generic attributes were developed by Council and announced to the University as part of a previous university strategic plan". Two institutions (P4 and P5) said it was also a grass-roots initiative, being led by academic developers who were 
promoting the use of outcomes as a core element of good learning design at the programme level.

Twelve of the 13 degree-granting institutions reported developing graduate profiles for compliance reasons imposed by accrediting bodies, eight because of an NZQA requirement, and four as it was a CUAP requirement. For example, the respondent from P3 commented "Graduate profiles have always been required as part of qualification development activity and this information has been required by NZQA". However, many institutions also have them to help ensure students' preparedness and others saw them as a key element of programme design. Although knowing they were fundamental to sound design, there was a recognition that much work still needed to be done in many institutions to embed them. This is illustrated at U1, where the respondent commented, "I would imagine that it was in recognition of the need to synchronise the whole programme. To be honest; links between the graduate profile; the curriculum design; learning outcomes and assessment are still an area that our unit has to do a lot of work with staff on. Some don't seem even to have encountered the concept before; let alone be able to articulate the reasons for it".

Five institutions (P2, P3, P4, U1, U7) said they did have a framework for the development of graduate outcomes, whilst another commented "No - it was a fraught process. In revising of graduate profile a working group with representation across the university was tasked with this. At programme level, lecturers develop them, often in response to professional bodies" (U6). In terms of the specific processes, some institutions used a mixture of course teams and working parties, while at others the graduate outcomes were developed by committees of academic stakeholders. Sometimes academic developers were brought on-board to assist with the process and in other cases they were developed through seminars with accrediting bodies. In many cases professional bodies or other community stakeholders were involved in the development of GPPs, particularly when local or provider qualifications were being developed. For example, the respondent from $\mathrm{P} 4$ said:

Under the new Tertiary Review of Qualifications over the next five years all stakeholders including industry and staff in the Industry Training sector from representative institutions will progressively work on all sub-degree level programmes; especially those covered by Unit Standards. 
In the universities, for more vocationally-oriented programmes in Engineering, Business, Education, Law, and Health Sciences there was close liaison with accrediting bodies in the development of GPPs.

\section{Use of graduate outcomes in the institution}

Graduate outcomes are used for a range of purposes in higher education institutions. Figures 4-6 show the various uses of graduate outcomes: administrative, pedagogical and other uses, but note there may be some overlap in categories. For example, although graduate outcomes may be required for programme approval, the reason for this is firmly grounded in a desire for sound pedagogical design of the programme.

Figure 4 shows the administrative use of graduate outcomes. In all institutions graduate profiles (either GPI or GPP) were required in the documentation for approval of new programmes. Most institutions also required them in the documentation for approval of new courses and six institutions used them to determine accreditation of prior learning.

Figure 5 shows the use of graduate outcomes for pedagogical purposes in the institutions. At the sub-programme level (i.e. for courses and modules), it is the graduate attributes that are the relevant graduate descriptor. In the polytechnics six out of the seven reported graduate attributes as being mapped throughout their programmes and intentionally aligned with learning outcomes and five said they were also aligned with assessment. For the universities, three said graduate attributes were mapped throughout their programmes and intentionally aligned with learning outcomes with two commenting that graduate attributes were also aligned with assessment. However, four universities reported that graduate attributes were mapped throughout some_degree programmes and only three said they were also aligned with assessment in some programmes. Eleven institutions reported using graduate attributes to provide guidance for students regarding the attributes they should acquire.

Figure 6 shows the use of graduate outcomes for other purposes. In most institutions graduate outcomes provide guidance for employers and other stakeholders about the attributes of graduates as well as being used for quality assurance purposes. Nine institutions also reported using them for quality enhancement purposes and in five institutions they are also used to inform extra-curricular activities. Two polytechnics reported also using them for marketing purposes.

[Figure 4 here]

[Figure 5 here] 
[Figure 6 here]

When asked about links between graduate outcomes and policies, out of the 15 institutions 10 responded, with eight saying graduate outcomes were linked to policies (P2, P3, P5, P7 and U1, U3, U4, U7), while a university and a polytechnic said they were not. Some examples given of graduate outcome inclusion in policies were programme portfolios, the institutional teaching and learning plan, and programme development, approval and accreditation policies. However, there was also recognition that while graduate outcomes may feature in policies, staff may not put these into practice. For example, one respondent said, "I don't in all honesty think that most teaching staff 'promote' the concept of graduate profiles albeit that they most often will have mapped and re-articulated graduate attributes in accordance with their discipline" (U3).

In only three institutions (P1, P2 and U2), teaching and learning awards emphasised engagement with graduate outcomes. However, in institutions where this was not a criterion, there was recognition that such engagement was part of good teaching practice. For example, one respondent commented "There is no emphasis but staff making links with them would receive a positive response from the committee" (U4).

In terms of informing managers and leaders about graduate outcomes, programme development processes were the main vehicle as well as an expectation that such leaders were expected to read policies. Most institutions informed their teaching staff of graduate outcomes through the processes of programme development, while four polytechnics (P1, P4, P5, P6) and three universities (U1, U5, U6) also used workshops and two others (P3, P6) ran specific courses. One university respondent commented on the process:

The ones who attend our workshops are inducted into the synchronicity of the whole deal. The ones who don't attend may well be inducted through their departments and faculties; but we still find ignorance of the process and importance of graduate profiles when we work with staff; including some who have been here a good while (U1).

Another university respondent (U6) commented on how the process could be very variable.

Seven institutions (three universities and four polytechnics) said they provided professional development support specifically for engagement with graduate outcomes, while two universities provided generic support. Such support was typically provided by academic developers, professional development bodies, and senior academics. Five institutions (two 
universities and three polytechnics) said no professional development support was in place to promote the use of graduate attributes in curricula.

Despite many institutions having policies for graduate outcomes, there was a recognition that staff can be remiss about reading and enacting policies.

Most institutions said they inform students about graduate outcomes through student handbooks which are given to students at enrolment but, like staff, it cannot be assumed that students will read this material. Thus there are usually other mechanisms put in place to inform students of graduate outcomes, although the widespread use of a range of such means is not guaranteed. For example, U7 said:

This is impossible to characterize for the entire University. Some students, in some programmes, will be provided with more information in these areas, such as through pre-employment briefings or capstone courses or experiences. Others, will have very little engagement or recognition of anything outside course-bycourse learning objectives and outcomes.

So, as well as handbooks, other methods include teachers discussing graduate outcomes as part of their courses, institutional induction processes, student learning and career advisors, and discussions with employers.

Six institutions (P3, P4 and U1, U3, U5) have no processes to help students track attainment of graduate outcomes, but five polytechnics (P1, P2, P5, P6, P7) said they use formative, summative assessment workplace-based learning allowing learners to receive real time feedback. Three polytechnics, (P2, P3 and P7) help students to actively track their progress towards attainment of graduate outcomes by comparing learning outcomes and achievement at the end of course, and/or students have to produce a portfolio at the end of their studies. The process is more variable in universities, but in professional courses, it is more likely that there will be processes to help students track attainment of graduate outcomes. Some universities use ePortfolios - either for specific programmes (U6) or more widely (U2).

\section{Measurement and monitoring of graduate outcomes}

Five institutions (P5, P6 and U1, U3, U6) said they use both formative and summative assessment to measure graduate outcomes. A university respondent (U6) said "One would expect that attributes are embedded in the papers and assessment and that achievement of grades in papers/assessments let students see whether and how well they are developing the qualities and skills needed". However, it was recognised that while assessment should be well aligned 
with outcomes, the link may not always be that clear - particularly to students. As Figure 5 shows, most institutions have graduate outcomes aligned with assessment in either all or some programmes.

In two polytechnics (P2 and P6) assessment was always aligned with the graduate profile, and in three more it was mostly aligned. In the universities it was more common for assessment to be sometimes aligned with the graduate profile and in five universities sometimes course evaluations asked about achievement of some of the graduate outcomes. In P3 and U2 all course evaluations asked about achievement of all graduate outcomes (i.e. achievement of the graduate profile).

Several institutions do not have an institutional graduate profile, but for those that do, this tends to be measured through assessment processes (though with varying levels of alignment), surveys of graduates reporting on perception of attainment of graduate outcomes, data for accreditation, graduating year review and quality assurance processes, and feedback from employers. At the programme level, monitoring methods include assessment (but again with varying levels of alignment), quality assurance processes, feedback from employers, course evaluations, accreditation and graduating year review processes. Graduate surveys are also used to monitor attainment of graduate outcomes and occasionally alumni are surveyed as well. Across all institutions the most common form of monitoring was via data for quality assurance processes, followed by employer feedback, data for accreditation processes and data for graduate year reviews. Four institutions (P6, U1, U2, and U7) also reported surveying alumni for feedback on attainment of graduate outcomes.

When asked why monitoring of graduate outcomes was undertaken, the reasons given included this being an integral part of self-evaluation and engagement with continuous quality improvement and assurance, as well as to ensure relevance and currency for students and stakeholders.

It was apparent that not many institutions were routinely informing staff and students of the results from monitoring graduate outcomes. Although staff were sometimes informed of monitoring results, students were seldom informed. For the few that did inform staff and students, mechanisms used included reports from surveys, employer, alumni and other stakeholder consultation, graduating year reviews and accreditation reports. One respondent (U7) commented: 
This depends on the college and/or programme involved. Externally accredited programmes tend to have higher levels of briefings for staff regarding the processes and monitoring of students' attainment of graduate profiles. Informing students of these same processes is generally a less common occurrence. In accomplishing this, graduating year reviews and accreditation reports are probably the two most common and recognized forms of monitoring the progress and attainment of graduate profiles. Depending on the specific programme, these may or may not also require programme-wide briefings for academic staff and, on occasion, students.

\section{Overall engagement with graduate outcomes}

Figure 7 uses the results of the Maturity Modelling to show each institution's rating of how strongly they are engaged with the six indicators: planning, systems, delivery, assessment, evaluation and professional development support for graduate outcomes. Regarding overall engagement with graduate outcomes, there is reasonable to strong engagement with the planning, systems and delivery of a graduate outcome agenda, but much lower engagement with assessment and evaluation of graduate outcomes and six institutions report weak or very weak professional development support for graduate outcomes. Five of the seven polytechnics reported reasonable to very strong engagement with planning, systems, delivery and assessment of graduate outcomes. However, there were lower levels of engagement with evaluation of graduate outcomes and professional development support, with the exception of one polytechnic. For the universities, two reported stronger levels of engagement, particularly with planning and systems, and one also reported strong engagement with delivery, assessment and evaluation. In contrast the five other universities reported mainly weak or reasonable engagement for all aspects.

[Figure 7 here]

\section{Discussion and Conclusions}

The first aim of our research was to develop a systematic way to gauge the level of engagement with graduate outcomes by institutions. The use of Maturity Modelling with six indicators of engagement can provide utility at both the institutional and national higher education levels. For example, institutions could use the approach to gauge their level of engagement, identifying areas of strength and areas where improvements are required. When the approach is 
implemented across the higher education sector, comparisons can be made between different parts of the sector (e.g., universities and polytechnics), and different institutions, as well as comparing levels of engagement with the different indicators. Such information is likely to be of use to those with responsibility for higher education policy, as well as organisations tasked with supporting the higher education sector.

The second aim was to use this systematic method to identify the current level of engagement with graduate outcomes by higher education institutions in Aotearoa/New Zealand. The analysis suggests that engagement with graduate outcomes in 14 higher education institutions in Aotearoa/New Zealand is at best patchy. That is, there are areas where graduate outcome engagement is strong, and other areas where there is less evidence of engagement. While there is reasonable to strong engagement with the planning, systems and delivery of graduate outcomes, particularly in the polytechnic sector, there is much lower engagement with the assessment and evaluation of graduate outcomes, and overall, weak engagement with professional development support for graduate outcomes. While many survey participants felt that graduate outcomes should be used as an integral part of curriculum design, they noted that there are issues with how they are developed, particularly regarding stakeholder input, and how they are embedded within curricula. The qualitative data from the interviews reinforce these results.

Figure 8 shows a continuum of engagement with graduate outcomes from weak to strong, together with key influencing factors. As a generalisation, universities tended to be located on the left hand side of the continuum whilst the polytechnics tended to be located on the right. The main reasons for the stronger engagement evident in the polytechnic sector were associated with external drivers (e.g., NZQA, professional bodies and accrediting bodies), a teaching-focussed culture, strong leadership from the top and enabling structures. Conversely, institutions that were less engaged typically placed less emphasis on external drivers and were more focussed on research. They tended to lack senior leadership in the graduate outcome agenda -instead relying on individual champions. In these institutions, the graduate outcome agenda was more poorly resourced and lacked authorised supporting structures.

[Figure 8 about here]

There is a paucity of research with which to compare our results. We have not located any similar research for Aotearoa/New Zealand, nor more widely. Our continuum of engagement in Figure 8 shows some similarities with this past research in terms of enablers - particularly the 
need for leadership and enabling structures such as staff development (e.g., see Hughes \& Barrie 2010; Sharp \& Sparrow 2002). However, by virtue of our study being across the tertiary sector, we also identified the importance of external drivers and a teaching-focussed culture as key enablers.

Our study had several limitations. Ideally we wanted to provide a comprehensive stocktake across the higher education sector reporting on engagement with graduate outcomes for universities, polytechnics and wānanga. However, we only gained a $48 \%$ response rate to our survey. Whilst this is a good response by higher education research standards, it meant that rather than being able to provide a comprehensive stocktake of the status of play, our study is more of an exploratory one. Moreover, it was unfortunate that we did not get any wānanga participating, so we are unable to comment on their level of engagement with graduate outcomes. In collecting data for our stocktake we targeted leaders of teaching and learner centres, since we felt they were the most likely group to know about initiatives and whether policy was being enacted. It was clear from our data that bringing about curriculum change can be highly political, and thus it was not surprising that our survey respondents and interviewees were quick to point out that the view being shared was a personal one, rather than representing the institution. Whilst this may limit what conclusions we can draw, we do feel that we have a strong dataset, and one from a group of leaders that are, in this case, the most relevant, since they often oversee the enactment of curriculum initiatives.

Our research has provided a systematic way to evaluate engagement with graduate outcomes within higher education institutions, as well as presenting much needed insight into engagement with graduate outcomes at both polytechnics and universities in Aotearoa/New Zealand. Given the engagement is limited, particularly for the university sector, it is important to take the next step to identify which factors promoted engagement with graduate outcomes in our sample. Whilst some mechanisms for promoting engagement were revealed in our analysis, such as strong external drivers, a teaching-focussed culture, strong leadership from the top and enabling structures, a more in-depth analysis of the interview data from leaders of teaching and learning centres would enable the development of a framework to illustrate enablers of engagement with graduate outcomes. This focus is pursued in an ensuing article by YYYY et al., (2014).

\section{Acknowledgements}


This research was supported through the Ako Aotearoa National Project Fund 2011. Thanks are due to our project advisor Simon Barrie.

\section{References}

Adelman, C. (2008). The Bologna Club: What U.S. higher education can learn from a decade of European reconstruction. Washington, DC: Institute for Higher Education Policy.

Adelman, C., Ewell, P., Gaston, P., \& Schneider, C. G. (2011). The degree qualifications profile. Indianapolis: Lumina Foundation for Education Inc.

Australian Qualifications Framework (AQF) Council (2011). Australian Qualifications Framework, First Edition 2011. Available at: http://www.aqf.edu.au/Portals/0/Documents/Handbook/AustQuals\%20FrmwrkFirstEditionJul y2011 FINAL.pdf (Accessed August 1 2012).

Barrie, S. C. (2004). A research-based approach to generic graduate attributes policy, Higher Education Research \& Development, 23, 3, 261-275.

Barrie, S. C. (2006). Understanding what we mean by the generic attributes of graduates. Higher Education, 51, 215-241.

Barrie, S. C., Hughes, C., \& Smith, C. (2009). The national graduate attributes project: integration and assessment of graduate attributes in curriculum. Australian Learning and Teaching Council: Strawberry Hills.

Bath, D., Smith, C., Stein, S., \& Swann, R. (2004). Beyond mapping and embedding graduate attributes: bringing together quality assurance and action learning to create a validated and living curriculum. Higher Education Research \& Development, 23(3), 313-328.

Bologna Declaration (1999), The European Higher Education Area, Joint Declaration of the European Ministers of Education, convened in Bologna, 19 June 1999. URL http://www.bologna-berlin2003.de/pdf/bologna_declaration.pdf. Accessed 23, 82012

YYYY. (2014). Academic leaders' views of key enablers in the development of graduate attributes: a framework for practice. (Paper in preparation)

Bowden, J., Hart, G., King, B., Trigwell, K., \& Watts, O. (2000). Generic Capabilities of ATN University Graduates. Sydney: University of Technology Sydney.

Dale, R. (2008). Changing Meanings of "the Europe of Knowledge" and "Modernizing the University," from Bologna to the "New Lisbon'. European Education, 39(4), 27-42. 
de la Harpe, B., Radloff, A., \& Wyber, J. (2000). Quality and Generic (Professional) Skills. Quality in Higher Education, 6(3), 231-243.

González, J., \& Wagenaar, R. (Eds.) (2003). Tuning Educational Structures in Europe. Final Report: Phase I. Groningen: University of Groningen.

Hager, P., Holland, S., \& Beckett, D. (2002). Enhancing the learning and employability of graduates: the role of generic skills Business/Higher Education Round Table Position Paper No 9. Melbourne: B-HERT.

Hughes, C., \& Barrie, S. (2010). Influences on the assessment of graduate attributes in higher education. Assessment \& Evaluation in Higher Education, 35(3), 325-334.

Kehm, B. M. (2010). European education. The influence of the Bologna process. Change, 42 May/June (3), 40-46.

Marshall, S., \& Mitchell, G. (2003). Potential indicators of e-learning process capability. Paper presented at the EDUCAUSE in Australasia 2003 Conference, Adelaide, Australia.

New Zealand Qualifications Authority (NZQA). (2013). Targeted review of qualifications. Available at: http://www.nzqa.govt.nz/studying-in-new-zealand/nzqf/targeted-review-ofqualifications/ (Accessed March 2013).

New Zealand Qualifications Authority (NZQA). (2011). The New Zealand Qualifications Framework. Wellington: NZQA.

Pitman, T., \& Broomhall, S. (2009). Australian universities, generic skills and lifelong learning. International Journal of Lifelong Learning, 28, 4, 439-458.

Sharp, S., \& Sparrow, H. (2002, 5-6 February). Developing frameworks to embed graduate attributes in tertiary courses. Paper presented at the Proceedings of the 11th Annual Teaching Learning Forum: Focusing on the Student, Perth, Edith Cowan University.

XXXX. (2013). Graduate outcomes: Are they driving learning? Wellington: Ako Aotearoa, 138pp. Available at: http://akoaotearoa.ac.nz/graduate-outcomes.

Thomas, D. R. (2006). A general inductive approach for analyzing qualitative data. American Journal of Evaluation, 27, 2, 237-246.

\section{WORDCOUNT 6798}


Figure captions

Figure 1: Definitions of graduate outcomes, profiles and attributes that we adopt in this article.

Figure 2: Self-rating of the strength of the research and teaching culture at the participating institutions $(n=14)$.

Figure 3: Reasons given for why the institution has graduate outcomes $(n=14)$. NZQA is the New Zealand Qualifications Authority and CUAP is the Committee on University Academic Programmes.

Figure 4: The use of graduate outcomes for administrative purposes $(n=13)$. Note GP is graduate profile.

Figure 5: The use of graduate outcomes for pedagogical purposes $(n=13)$. LOs are learning outcomes.

Figure 6: The use of graduate outcomes for other purposes $(n=13)$. GP is graduate profile.

Figure 7: Institutional rating of engagement with graduate outcomes. $\mathrm{P}$ is polytechnic, $\mathrm{U}$ is university, and Prof Dev is professional development.

Figure 8: Continuum of engagement with graduate outcomes, from weaker engagement (in light grey) to stronger engagement (in black) with influencing factors shown above the arrow. 
Figure 1

$\underline{\text { Key to graduate attributes }}$

Across degree/institution "generic attributes" 


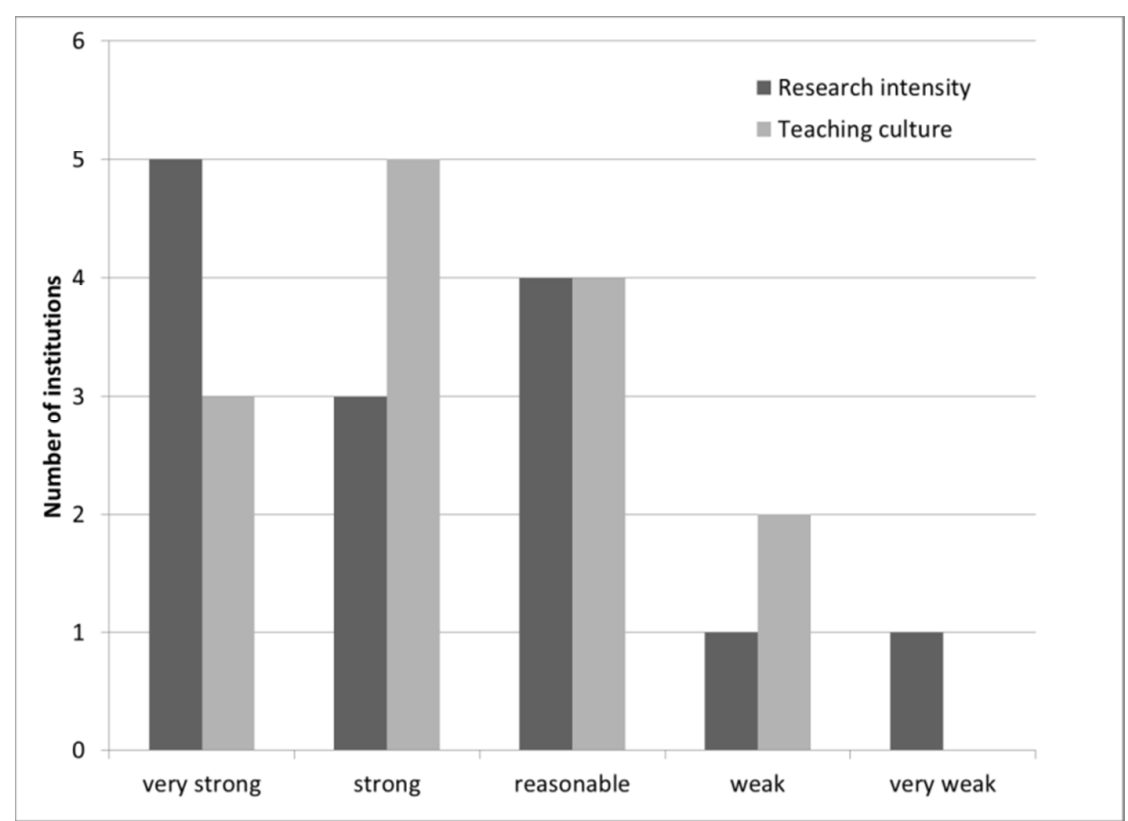

Figure 2

URL: http://mc.manuscriptcentral.com/cher Email: diana.herd@hotmail.co.nz 


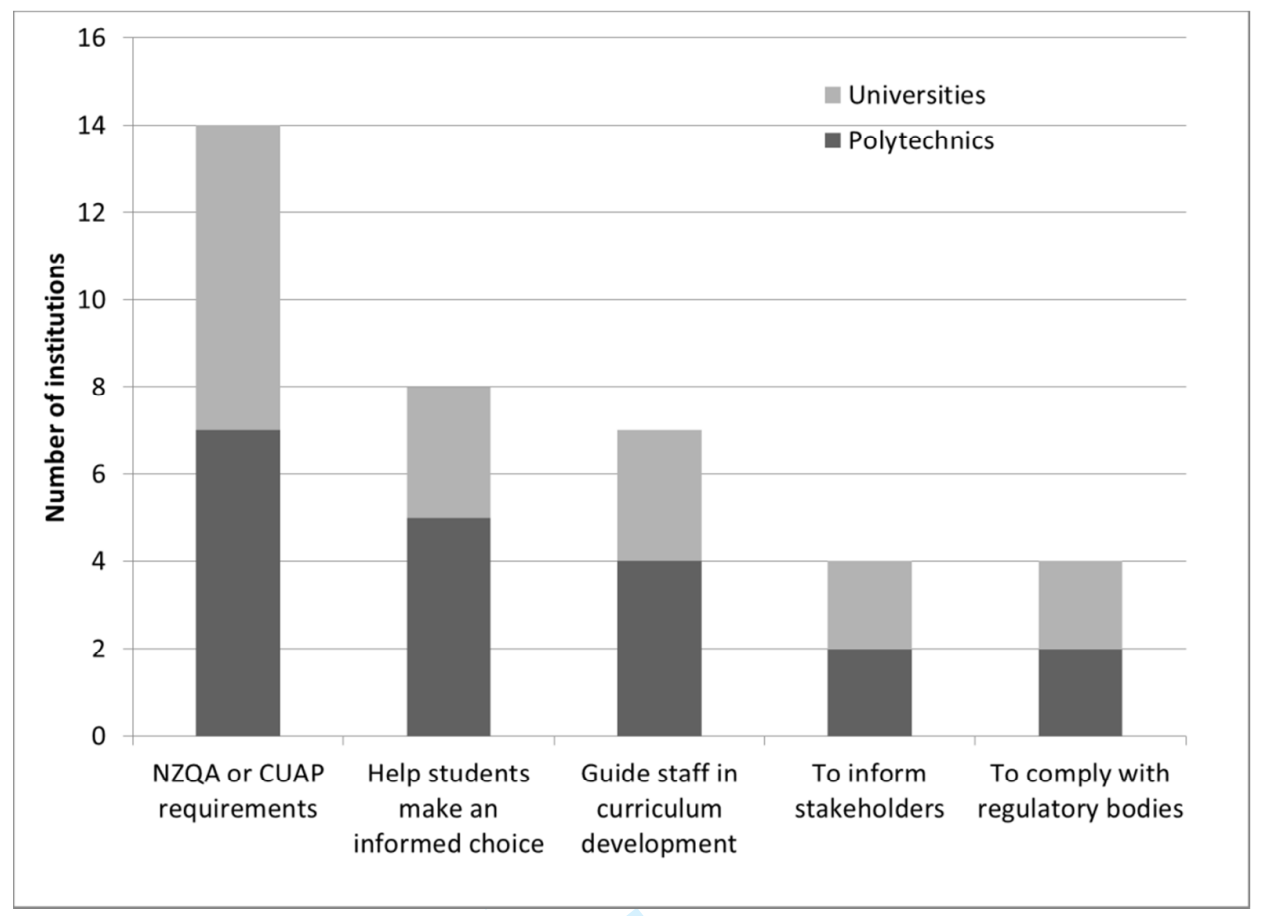

Figure 3 


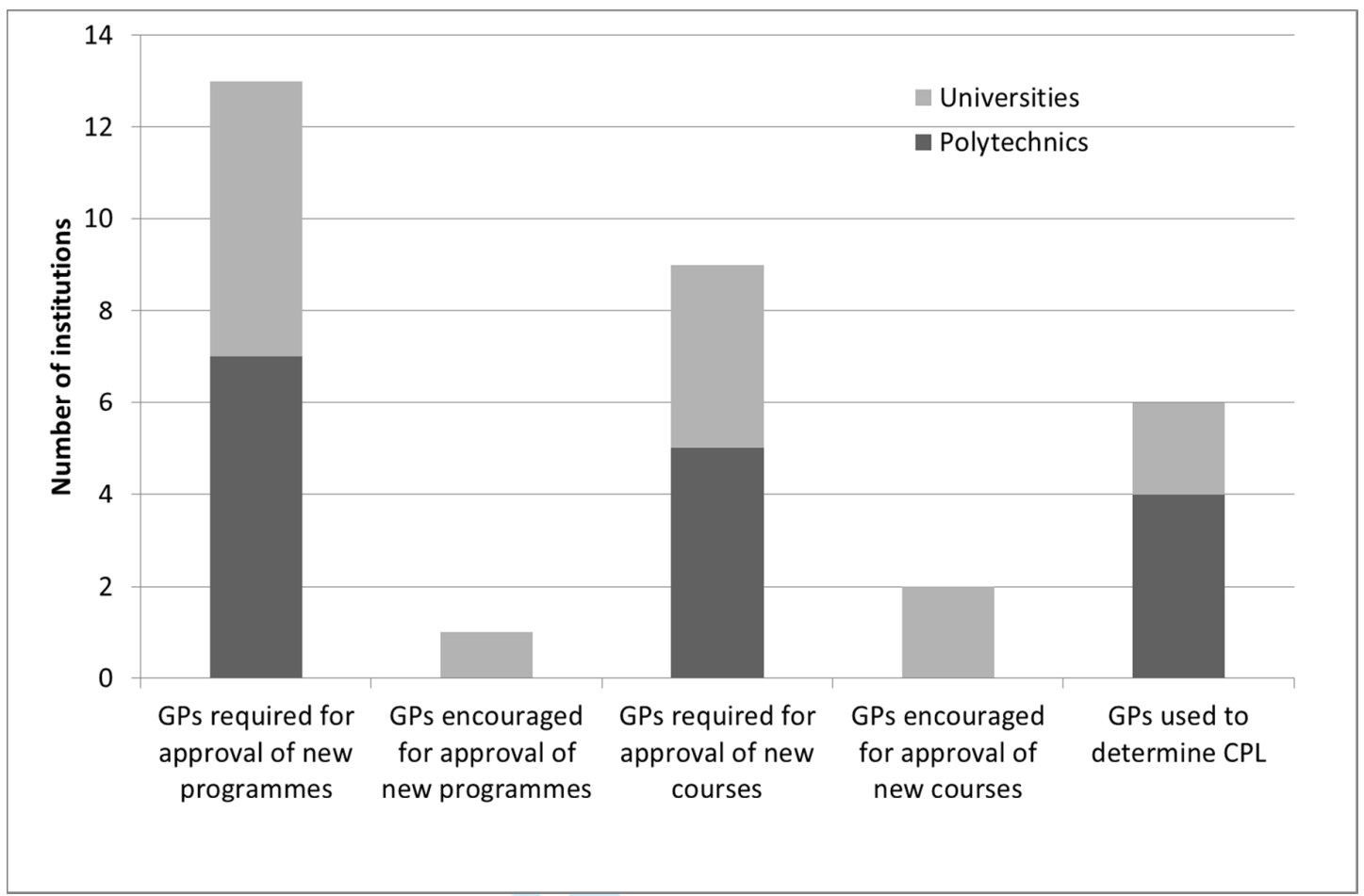

Figure 4 


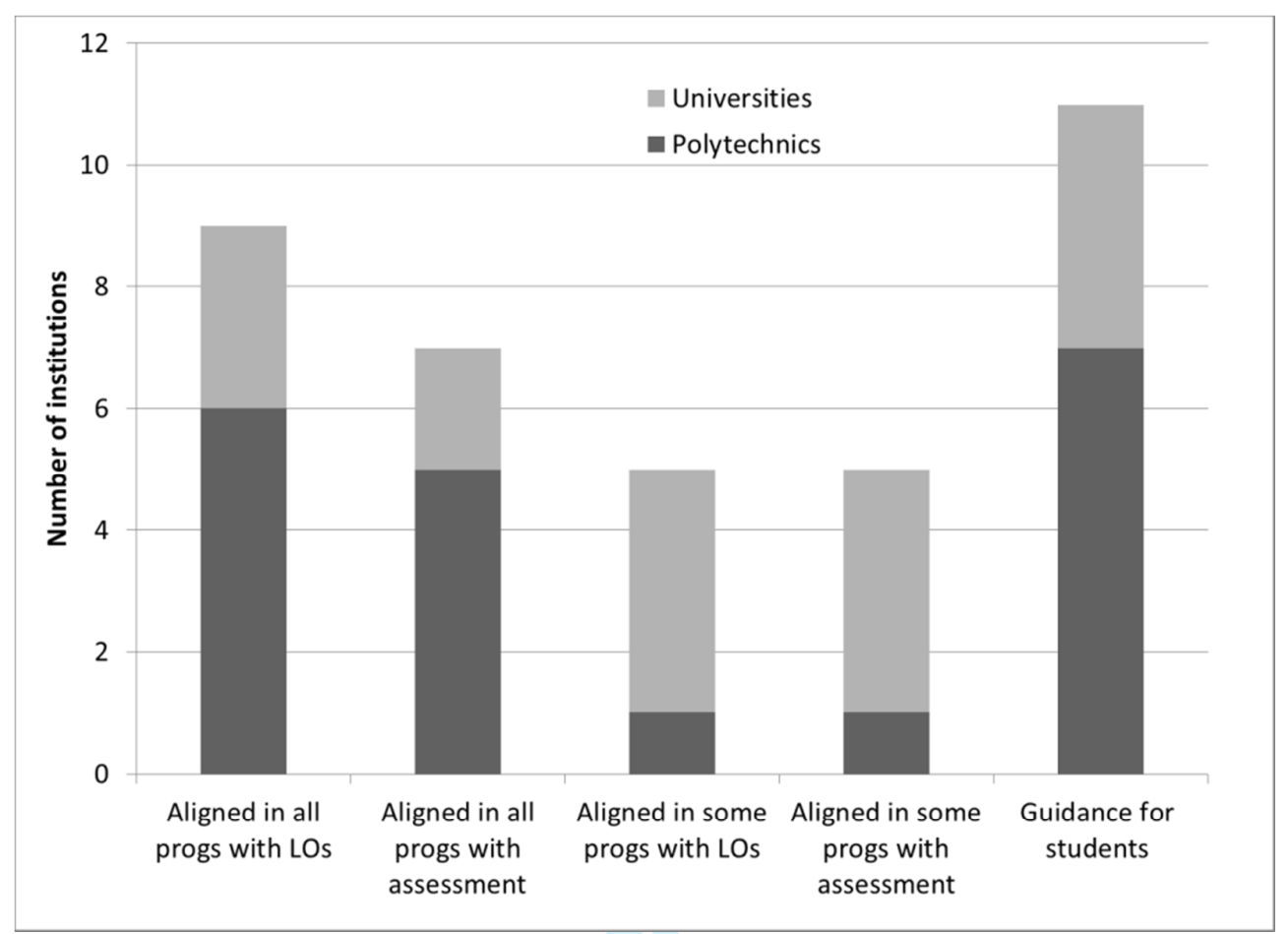

Figure 5

URL: http://mc.manuscriptcentral.com/cher Email: diana.herd@hotmail.co.nz 


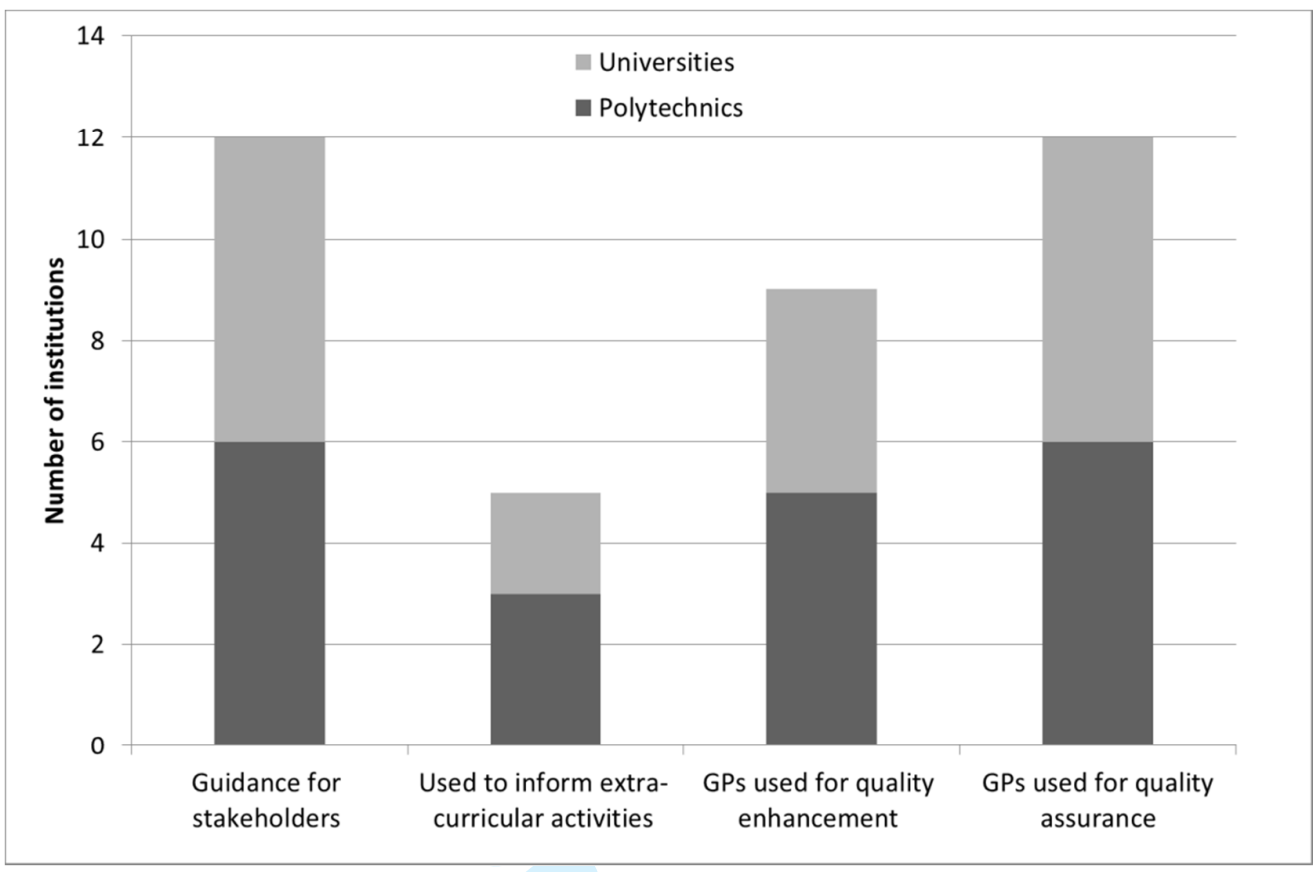

Figure 6 


\begin{tabular}{|c|c|c|c|c|c|c|}
\hline & Planning & Systems & Delivery & Assessment & Evaluation & $\begin{array}{c}\text { Prof dev } \\
\text { support }\end{array}$ \\
\hline P1 & & & & & \\
\hline P2 & & & & & \\
\hline P3 & & & & & \\
\hline P4 & & & & & \\
\hline P5 & & & & & \\
\hline P6 & & & & & \\
\hline P7 & & & & & \\
\hline U1 & & & & & \\
\hline U2 & & & & & \\
\hline U3 & & & & & \\
\hline U4 & & & & & \\
\hline U5 & & & & & \\
\hline U6 & & & & & \\
\hline U7 & & & & & \\
\hline
\end{tabular}

\section{Legend:}

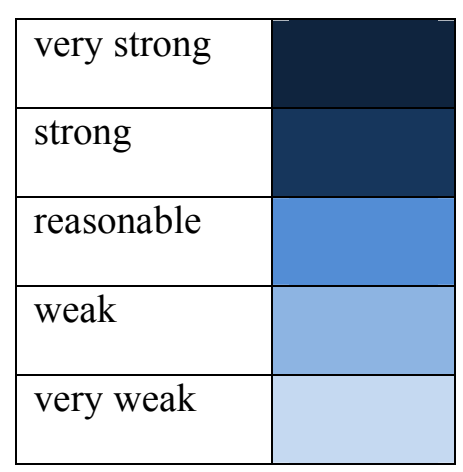

Figure 7 
- Lacking external drivers

- Research-focused culture

- Relying on champions

- Patchy resourcing

- Patchy structures
- Strong external drivers

- Teaching-focused culture

- Strong leadership from the top

- Enabling structures

\section{Level of engagement}

Figure 8 